\title{
Structural and functional aspects of porcine endometrial capillaries on Days 13 and 15 after oestrus or mating
}

\author{
J. P. Laforest* and G. J. King † \\ Department of Animal and Poultry Science, University of Guelph, Guelph, Ontario, \\ Canada NIG $2 W I$
}

\begin{abstract}
Summary. The permeability of subepithelial capillaries in porcine endometrium was studied during midcycle and early pregnancy. Gilts were slaughtered on Day 13 or Day 15 of the oestrous cycle or pregnancy, $15 \mathrm{~min}$ after injection through the ear vein of $11 \cdot 1 \mathrm{MBq}$ of ${ }^{125}$ I-labelled human albumin in phosphate-buffered saline. The radioactivity of endometrial strips taken along the mesometrial and antimesometrial aspects of the uterine horn varied on average from 270 to 701 c.p.m./g and no difference $(P>0.05)$ was found between reproductive status, days of slaughter or sampling sites. The majority of the subepithelial capillaries showed ultrastructural evidence of increased vascular permeability, such as marked thinning of the capillary walls, especially on the side proximal to the epithelial basal lamina, multilayering and partial disparition of the endothelial basal lamina and abundant endothelial vesicles. Fenestrated pores were observed, but were rare. There was no obvious difference between reproductive status, days of sampling or sampling sites inside the uterus, suggesting that on Days 13-15 after oestrus the ultrastructural characteristics of porcine endometrial capillaries are little affected by the presence of attaching blastocysts and supporting the results obtained with radioactive albumin. Ferritin injected directly into a uterine artery of one gilt on Day 15 of pregnancy was carried through the capillary wall by endothelial vesicles, showing ultrastructural evidence of increased permeability.
\end{abstract}

Keywords: ferritin; radioactive albumin; endometrium; vascular permeability; pig

\section{Introduction}

An increase in the permeability of endometrial capillaries has been suggested as a universal prerequisite for the establishment of pregnancy in placental mammals (Psychoyos, 1973). This has been observed and quantified using albumin marked with a dye (rat: Psychoyos, 1960; hamster: Orsini, 1964; mouse: Finn \& McLaren, 1967; guinea-pig: Orsini \& Donovan, 1971; rabbit: Hoffman et al., 1978), radioactive albumin injected into the peripheral circulation (Psychoyos, 1961; BittonCasimiri et al., 1965), large molecules, such as horseradish peroxidase or ferritin (Parr \& Parr, 1985) and variation in water content of uterine tissues (Hoos \& Hoffman, 1980). Extravasation of albumin has been reported in sheep placentomes (Boshier, 1970) and ultrastructural modifications indicating increased vascular permeability were observed in pigs (Keys \& King, 1988). However, more experimental evidence is needed to support the hypothesis that an increase in vascular permeability is a prerequisite for the attachment process in species with epitheliochorial placentation.

$\div$ Reprint requests.

*Present address: Département de Zootechnie, Université Laval, Sainte-Foy, Québec, Canada GlK 7P4. 
No reports have indicated that the water content of the endometrium or the radioactivealbumin technique has been used in pigs to study the permeability of the blood vessels at the time of embryonic attachment. A first experiment was thus conducted to demonstrate an increase in permeability of the endometrial capillaries using iodinated albumin and measuring water content at localized sites along the uterine horn.

A second experiment was conducted to investigate whether anionic ferritin exited from the capillaries in association with pregnancy-associated ultrastructural changes in endothelium. A comparison between capillaries on the mesometrial and antimesometrial aspects was also included because the first signs of attachment in pigs always occur along the mesometrial aspect.

\section{Materials and Methods}

Animals and management. The experimental animals were sexually mature Yorkshire gilts of similar age $\left(\sim 250\right.$ days old) and weight $(90-120 \mathrm{~kg})$. Eight to twelve gilts were housed in a $3 \times 3.7 \mathrm{~m}\left(11.1 \mathrm{~m}^{2}\right)$ pen and floorfed $\sim 2.5 \mathrm{~kg}$ /day/animal with a $15 \%$ crude protein diet (maize-soyabean). Water was always available from drinking nipples. Gilts were checked daily for oestrus with a boar and allocated randomly to treatment after at least two oestrous cycles of normal length (19-22 days). The first day of standing oestrus was considered to be Day 0; pregnant group gilts were bred that day and again $12 \mathrm{~h}$ later.

Experiment 1. Four randomly selected, mated gilts presumed pregnant $(\mathrm{Pr})$ and four unmated cycling gilts were slaughtered on Day 13 after oestrus and the other four mated and unmated animals were slaughtered on Day 15. Gilts were injected through the ear vein with $50 \mathrm{ml}$ of a solution of iodinated albumin $\left(30 \mathrm{mg},{ }^{125}\right.$ I-labelled human albumin, $0.04 \mathrm{MBq} / \mathrm{mg}$; Merck Frosst Canada Inc., Montréal, Canada) in Dulbecco's phosphate-buffered saline (PBS; $\mathrm{pH} 7.4$; Gibco Laboratories, Grand Island, NY, USA). As gilts weighed $\sim 100 \mathrm{~kg}$ at the time of slaughter, each received $11 \cdot 1 \mathrm{kBq}(0.3 \mathrm{mCi}) / \mathrm{kg}$ body weight. After $15 \mathrm{~min}$, gilts were stunned by electrocution and exsanguinated. Blood samples were collected into $10 \mathrm{ml}$ heparinized tubes during bleeding.

Uteri were obtained within $10 \mathrm{~min}$ of slaughter and immediately placed on ice, as were the blood samples and a sample of the rectus abdominis muscle taken from the posterior region near the linea alba. Uterine horns were dissected from the mesometrium, cut open longitudinally along the antimesometrial aspect and sections $30 \mathrm{~cm}$ long were spread flat and pinned with the endometrial side up in a large dissecting tray. Mated animals were excluded if blastocysts were not found in the uteri after slaughter. Strips of endometrium $(2 \mathrm{~cm}$ wide and completely separated from the myometrium) were carefully cut along the mesometrial aspect and at sites parallel and at least $3 \mathrm{~cm}$ from the mesometrium (in triplicate). Approximately I $\mathrm{g}$ of each strip was placed at the bottom of a test tube. The exact sample weight was determined before measuring radioactivity for $10 \mathrm{~min}$ on a Searle gammaspectrometer with an estimated counting efficiency of $80 \%$. Samples of abdominal muscle were treated similarly, i.e. $\sim 1 \mathrm{~g}$ (in triplicate) was finely cut, packed into the bottom of a test tube, weighed and counted. Radioactive content of three aliquots each of both blood and plasma $(0.8 \mathrm{ml})$ was also determined. The radioactivity of all samples (plasma and blood included) expressed in counts per min (c.p.m.) was corrected according to the weight of the sample. Samples of $\sim 3 \mathrm{~g}$ of endometrial strips and of abdominal muscle were also taken in duplicate, weighed precisely and freeze-dried to determine the percentage of dry matter.

Data were analysed using the SAS GLM procedure (SAS, 1987). Whenever variation is reported it is always the standard error of the mean (s.e.m.). A split-plot design was used for both radioactivity and dry matter content, in which reproductive status and days of slaughter were the main plots in a $2 \times 2$ factorial, and sampling positions inside the uterus were the subplots (Snedecor \& Cochran, 1980). Main and secondary effects could be evaluated directly from the analysis of variance. Homogeneity of variance among treatments was confirmed using Burr-Foster's test (Anderson \& McLean, 1974). The radioactivity of the endometrial samples was analysed initially and after correction in proportion to the radioactivity in plasma, blood and muscle. Data on dry matter content were analysed initially and corrected for the dry matter content of the muscle samples.

Experiment 2. Eight randomly selected mated and unmated gilts were slaughtered on each of Days 13 and 15. For each treatment, two gilts received a solution of anionic ferritin (Sigma, St Louis, MO, USA; Ferritin type I, $1 \mathrm{~g} /$ gilt in $50 \mathrm{ml} 0.15 \mathrm{~mol}$ saline/1) by injection through the ear vein; the remaining six were not injected. Injected gilts were slaughtered $10 \mathrm{~min}$ after injection; non-injected gilts were slaughtered without delay. Uteri were obtained immediately after exsanguination and placed directly on ice. One horn chosen at random was dissected from the mesometrium, cut open longitudinally along the antimesometrial aspect and spread flat on a large dissecting tray with the endometrial side up. Mated animals were excluded if blastocysts were not found in the uteri after slaughter. Samples were usually taken for transmission electron microscopy (EM) within $15 \mathrm{~min}$ from the time the uterus was excised from the body cavity.

Two additional pregnant gilts (Day 15) were prepared for midventral laparotomy according to the method described by Keys et al. (1986). Gilts were checked for pregnancy by opening the tip of one uterine horn and looking for embryonic membranes. A concentrated solution of anionic ferritin (type I, $2 \mathrm{~g}$ per gilt in $10 \mathrm{ml} 0.15 \mathrm{~mol}$ saline $/ 1$, with $0.05 \mathrm{~g}$ of Evans blue as a visual marker) was injected directly into a major uterine artery of each gilt with minimal 
uterine manipulation. After $\sim 1 \mathrm{~min}$, a uterine section was removed, cut open longitudinally along the antimesometrial aspect and pinned in a dissecting tray immediately after removal. Samples were taken along the mesometrial aspect and processed for EM. Gilts were killed immediately after the uterine specimen was obtained.

From pregnant females, small endometrial samples $\left(\sim 1 \mathrm{~cm}^{2}\right)$ were taken near the trophectoderm, in a region devoid of trophectoderm, but along the mesometrium, and away from both trophectoderm and mesometrium (3-4 cm from the mesometrium). Samples from cycling gilts were taken from the mesometrial aspect and at $3-4 \mathrm{~cm}$ away. Tissues were fixed in $3 \%$ gluteraldehyde (in $0.1 \mathrm{~mol}$ phosphate buffer $/ 1 ; \mathrm{pH} 7 \cdot 2)$, fixed on ice with $\mathrm{OsO}_{4}(1 \%$ in $0.1 \mathrm{~mol}$ phosphate buffer $11+5 \cdot 4 \%$ dextrose; $\mathrm{pH} 7 \cdot 2)$, stained 'en bloc' overnight ( $2 \%$ aqueous uranyl acetate), dehydrated in graded series of ethanol solutions followed by propylene oxide and embedded in Araldite CY 212 (Marivac Ltd, Halifax, Canada). Gold sections (90-150 nm) were cut, stained for $15 \mathrm{~min}$ in a $50 \%$ ethanol solution containing $2 \%$ uranyl acetate, followed by 2 min of staining with aqueous Millonig's lead citrate.

Sections were taken from three blocks for each sampling site. Observations and micrographs were taken without knowing the treatments, to avoid any bias. Only subepithelial capillaries were observed with more attention to lumen size, wall thickness and uniformity, distance from epithelial basal lamina, nuclear position, fenestrated areas, aspect of the capillary basal lamina, and presence of caveolae or endothelial vesicles. No statistical analysis was conducted as no measurement was performed.

\section{Results}

\section{Experiment 1}

The amount of radioactivity in the endometrium varied from 278 to 701 c.p.m./g (480 \pm 107$)$. Average radioactivity of samples of muscle, plasma and blood (range in parentheses) were $82 \pm 21$ (49-132), $10950 \pm 1934$ (6907-14 449) and $6753 \pm 1161$ (4163-8609) c.p.m./g, respectively. No effect $(P>0.05)$ was found for reproductive status (pregnant vs. cycling), Day (13 vs. 15) or sampling site (meso- vs. antimesometrial aspects), whether results were expressed directly or in proportion to radioactivity in abdominal muscle, plasma or blood (Table 1). Correcting radioactivity of the endometrial samples according to dry matter content did not change these results.

Table 1. Radioactivity (c.p.m./g) of endometrial tissue of gilts after injection of $1 \cdot 11 \mathrm{MBq}$ of ${ }^{125}$ I-labelled human albumin during the oestrous cycle and early pregnancy

\begin{tabular}{|c|c|c|c|c|c|c|c|c|}
\hline $\begin{array}{l}\text { Reproductive } \\
\text { status }\end{array}$ & Day & $n$ & $\underset{\text { site }}{\text { Sampling }}$ & $\mathrm{I}^{*}$ & II & $\begin{array}{l}\text { III } \\
\times 10^{-2}\end{array}$ & $\begin{array}{l}\text { IV } \\
\times 10^{-2}\end{array}$ & $\mathrm{~V}$ \\
\hline \multirow[t]{4}{*}{ Pregnant } & 13 & 4 & M & 522 & $6 \cdot 88$ & 4.92 & 8.65 & $46 \cdot 9$ \\
\hline & & & A & 447 & $5 \cdot 82$ & $4 \cdot 19$ & $7 \cdot 35$ & $39 \cdot 3$ \\
\hline & 15 & 4 & $\mathrm{M}$ & 458 & $5 \cdot 29$ & $3 \cdot 96$ & $6 \cdot 16$ & 36.8 \\
\hline & & & A & 460 & $5 \cdot 29$ & 3.95 & $6 \cdot 16$ & $36 \cdot 5$ \\
\hline \multirow[t]{4}{*}{ Cycling } & 13 & 4 & $\mathrm{M}$ & 422 & 6.53 & $4 \cdot 21$ & $7 \cdot 03$ & $34 \cdot 1$ \\
\hline & & & A & 436 & 6.76 & $4 \cdot 46$ & $7 \cdot 44$ & $34 \cdot 6$ \\
\hline & 15 & 4 & $\mathrm{M}$ & 559 & $6 \cdot 21$ & 5.03 & 7.79 & $47 \cdot 1$ \\
\hline & & & A & 535 & $6 \cdot 06$ & $4 \cdot 84$ & $7 \cdot 41$ & $45 \cdot 1$ \\
\hline \multicolumn{9}{|c|}{ Level of significance ( $P \leqslant$ value) } \\
\hline \multicolumn{4}{|c|}{ Reproductive status $(\mathrm{R})$} & 0.949 & 0.815 & $0 \cdot 702$ & 0.928 & 0.995 \\
\hline \multirow{2}{*}{\multicolumn{4}{|c|}{ Day (d) }} & 0.584 & 0.646 & 1.000 & 0.666 & 0.820 \\
\hline$R \times d$ & & & & 0.208 & 0.959 & 0.260 & 0.255 & 0.074 \\
\hline \multicolumn{4}{|c|}{ Sampling site (S) } & 0.243 & 0.389 & 0.502 & 0.440 & $0 \cdot 162$ \\
\hline \multicolumn{4}{|c|}{$\mathrm{R} \times \mathrm{S}$} & 0.553 & $0 \cdot 238$ & $0 \cdot 332$ & 0.378 & 0.425 \\
\hline \multicolumn{4}{|l|}{$\mathrm{d} \times \mathrm{S}$} & 0.830 & 0.712 & 0.918 & 0.978 & 0.682 \\
\hline \multicolumn{4}{|l|}{$\mathrm{R} \times \mathrm{d} \times \mathrm{S}$} & $0 \cdot 121$ & $0 \cdot 154$ & $0 \cdot 143$ & $0 \cdot 116$ & $0 \cdot 148$ \\
\hline \multicolumn{4}{|l|}{$C V(\%)$} & $22 \cdot 2$ & $29 \cdot 6$ & $23 \cdot 0$ & $25 \cdot 7$ & $24 \cdot 7$ \\
\hline
\end{tabular}

*I, c.p.m./g in endometrial sample; II, I/(c.p.m./g in abdominal muscle); III, I/(c.p.m./g in plasma);

IV, I/(c.p.m./g in blood $) ; \mathrm{V},(\mathbf{I} \times \%$ dry matter of endometrial sample $) / 100$.

tMesometrial (M) and antimesometrial (A) aspects of the uterine horn. 
The dry matter content of the endometrial tissues was, on average, $12 \cdot 1 \pm 0 \cdot 9 \%(9 \cdot 8-14 \cdot 1)$ and was not influenced $(P>0.05)$ by reproductive status, day of slaughter or sampling site. Correction of the dry matter content of the endometrial samples in proportion to the dry matter content of the abdominal muscle samples gave similar results (Table 2).

Table 2. Dry matter content (\%) of endometrial tissue of gilts during the oestrous cycle and early pregnancy

\begin{tabular}{|c|c|c|c|c|c|}
\hline $\begin{array}{l}\text { Reproductive } \\
\text { status }\end{array}$ & Day & $n$ & $\begin{array}{c}\text { Sampling } \\
\text { site* }^{*}\end{array}$ & $\begin{array}{c}\text { Dry matter } \\
\text { of sample }(\%)\end{array}$ & $\begin{array}{l}\text { Dry matter of sample } \\
\text { Dry matter of muscle }\end{array}$ \\
\hline \multirow[t]{4}{*}{ Pregnant } & \multirow[t]{2}{*}{13} & \multirow[t]{2}{*}{4} & M & $11 \cdot 4$ & 0.49 \\
\hline & & & A & $11 \cdot 5$ & $0 \cdot 50$ \\
\hline & \multirow[t]{2}{*}{15} & \multirow[t]{2}{*}{4} & M & $12 \cdot 4$ & 0.58 \\
\hline & & & A & $12 \cdot 6$ & 0.58 \\
\hline \multirow[t]{4}{*}{ Cycling } & \multirow[t]{2}{*}{13} & \multirow[t]{2}{*}{4} & M & $12 \cdot 3$ & 0.53 \\
\hline & & & A & $12 \cdot 5$ & 0.54 \\
\hline & \multirow[t]{2}{*}{15} & \multirow[t]{2}{*}{4} & M & $11 \cdot 8$ & 0.52 \\
\hline & & & A & $11 \cdot 9$ & 0.52 \\
\hline \multicolumn{6}{|c|}{ Level of significance ( $P \leqslant$ value) } \\
\hline \multicolumn{4}{|c|}{ Reproductive status ( $\mathbf{R})$} & 0.933 & 0.933 \\
\hline \multicolumn{4}{|c|}{ Day (d) } & $0 \cdot 846$ & $0 \cdot 212$ \\
\hline \multicolumn{4}{|l|}{$R \times d$} & 0.087 & $0 \cdot 092$ \\
\hline \multicolumn{4}{|c|}{ Sampling site (S) } & $0 \cdot 178$ & $0 \cdot 176$ \\
\hline \multicolumn{4}{|c|}{$\mathrm{R} \times \mathrm{S}$} & 0.985 & 0.974 \\
\hline \multicolumn{4}{|l|}{$\mathrm{d} \times \mathrm{S}$} & 0.913 & $0 \cdot 943$ \\
\hline \multicolumn{4}{|l|}{$R \times d \times S$} & 0.748 & 0.697 \\
\hline \multicolumn{4}{|l|}{$C V(\%)$} & $7 \cdot 5$ & $10 \cdot 5$ \\
\hline
\end{tabular}

*Mesometrial (M) and antimesometrial (A) aspects of the uterine horn.

\section{Experiment 2}

Structural characteristics of the capillaries. One gilt from pregnancy Day 13 and two gilts from pregnancy Day 15 groups were discarded because no embryo could be found. Processing problems were encountered with several other specimens so final numbers examined by EM were 6 on cycling Day 13, 6 on pregnancy Day 13,4 on cycling Day 15 and 4 on pregnancy Day 15.

EM observations were exclusively on capillaries that were closer than the height of one epithelial cell $(\sim 40 \mu \mathrm{m})$ from the epithelial basal lamina. The capillaries were first separated according to their distance from the epithelial basal lamina. Only $8 \%$ (30 of 376) of the capillaries recorded were farther from the epithelial basal lamina than approximately half the height of an epithelial cell. Of the remainder, 37\% (138 of 376) were directly adjacent (almost touching, i.e. at $\sim 0.5-1.0 \mu \mathrm{m}$ ) to the epithelial basal lamina whereas the others were classified as close, but not contiguous. In the range of distance chosen, no apparent difference was found between reproductive status, days of slaughter or sampling sites, in regard to the number of capillaries close or far from the epithelium although the actual distances were not measured.

In all sections, capillaries that were farther than approximately half the height of an epithelial cell from the epithelial basal lamina generally had thicker walls than closer capillaries. Nevertheless, most capillaries had thin walls with large lumens (Fig. la). Intraluminal projections (filopodia) were occasionally found, but their length and number seemed to vary as much within sections as between animals, so no obvious effect of reproductive status or day of slaughter was found. The wall proximal to the epithelium was thinner than the distal wall in approximately half of the capillaries, but thinner distal walls were not encountered. Thinner proximal walls were particularly frequent for capillaries adjacent to the epithelial basal lamina. On some occasions, short, very thin 
and straight areas were present along the capillary wall, suggesting the beginning of a transformation from a thick to a thin capillary wall or formation of fenestrated areas. Endothelial cells were always joined by extensive junctional complexes with zonula occludente on the luminal side of the capillaries. Gaps between cells were not found.

(a)

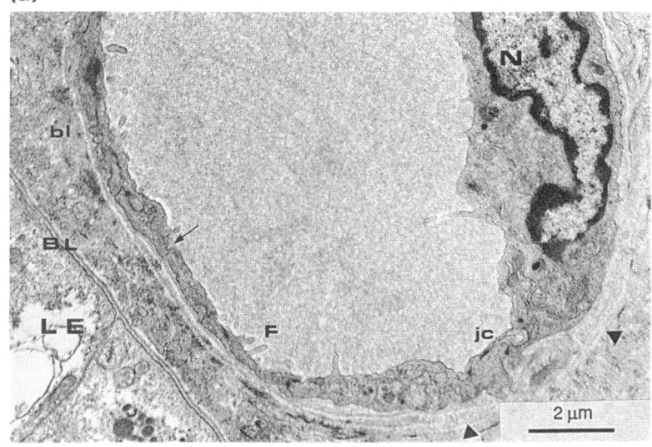

(c)

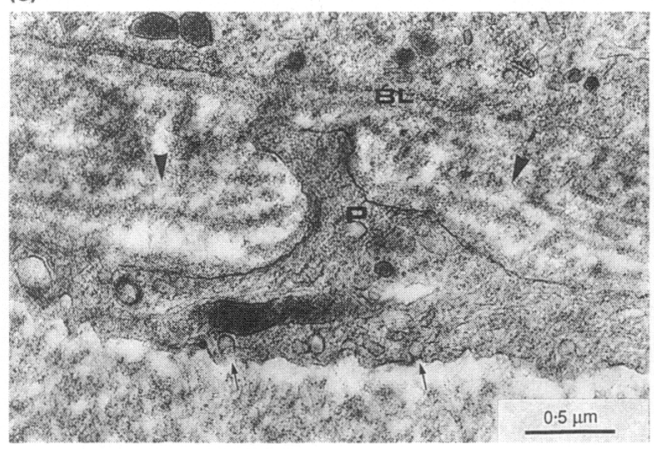

(b)

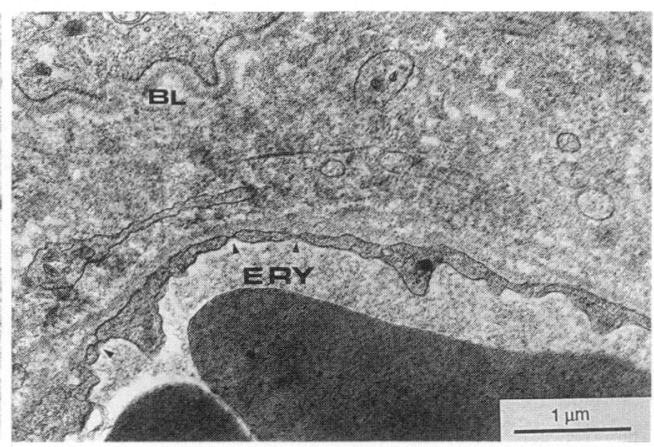

(d)

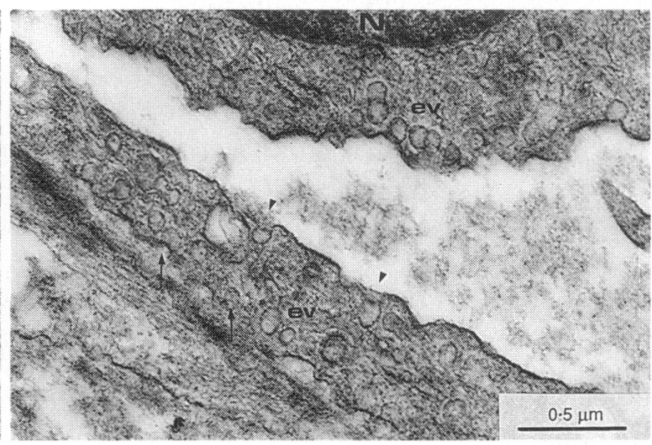

Fig. 1. Electron micrographs of subcpithelial capillaries in the uterus of cycling Day 15 (a and b) and cycling Day 13 (c and d) gilts. (a) The luminal epithelium (LE) is underlain by a welldefined basal lamina (BL). The capillary wall is thinner on the side proximal to the epithelial basal lamina, and endothelial cells are joined by junctional complexes (jc). The nucleus $(\mathrm{N})$ occupies a large portion of the distal capillary wall and some filopodia (F) are seen in the lumen. Parts of the capillary basal lamina (bl) are distinctly multilayered (arrowheads). Caveolae (arrow) are present on the luminal side. (b) The luminal epithelium lies beyond the upper part of the micrograph. The capillary lumen is filled with erythrocytes (ERY). Three fenestrations closed with a diaphragm (arrowheads) are present along the capillary wall proximal to the epithelial basal lamina (BL). (c) The luminal epithelium of the uterus lies at the top of the micrograph. An endothelial projection (P) seems to go through the multilayered endothelial basal lamina (arrowheads) and closely approaches the epithelial basal lamina (BL). Endothelial vesicles and caveolae (arrows) can be seen along the capillary wall. (d) The luminal epithelium of the uterus lies beyond the lower left corner of the micrograph. Some caveolae at different stages of formation can be seen on the luminal side of the capillary wall (arrowheads), but also on the stromal side (arrows). Endothelial vesicles are numerous along the attenuated endothelium proximal to the epithelial basal lamina (ev), but also near the endothelial cell nucleus (N).

Of 376 capillaries observed, 36 had 'fenestrated-like' structures. Most structures counted as fenestrations presented characteristic diaphragm-closed pores (Fig. 1b). There were usually one or two fenestrations, but some capillaries had four to six in a row. Fenestrations were seen only in capillaries adjacent to the epithelial basal lamina and always on the proximal wall. When more than one fenestrated pore was present, the pores were usually close to one another in the same stretch of 
capillary wall, suggesting that these structures are not evenly distributed, but regrouped in specific areas along the capillaries. Neither reproductive status nor day of slaughter seemed to influence the number of fenestrations. The actual number of capillaries with fenestrated areas in proportion to the total number of capillaries observed was as follows: 6 of $127(4.7 \%)$ on cycling Day 13,12 of 70 $(17 \cdot 1 \%)$ on cycling Day 15, 16 of $116(13 \cdot 8 \%)$ on pregnancy Day 13, and 2 of $63(3 \cdot 2 \%)$ on pregnancy Day 15.

Endothelial cell nuclei were distal or lateral to the luminal epithelium (Fig. 1a), especially in capillaries very close to the epithelial basal lamina. Some capillaries also had nuclei proximal to the luminal epithelium, but distal and lateral nuclei were more frequent. About $80 \%$ of all nuclei were in distal and lateral positions in respect to the position of the luminal epithelium.

The endothelial basal lamina was generally discontinuous with multilayered areas (Fig. 1a) and not as well defined as the epithelial basal lamina. Three capillaries in sections from two pregnancy Day 15 and one cycling Day 13 gilts clearly presented projections of the endothelial cell through the endothelial basal lamina (Fig. 1c). The endothelial basal lamina was sometimes absent on the side proximal to the luminal epithelium for capillaries adjacent to the epithelial basal lamina. However, the epithelial basal lamina was always present and continuous.

Caveolae were seen and endothelial vesicles were particularly frequent (Fig. 1d). No constant pattern could be associated with either reproductive status or day of slaughter, wide variations occurring from one capillary to another in the same section. These structures were more frequent in capillaries adjacent to the luminal epithelium, but were rare or absent in thick-walled regions. Overall, all sampling sites seemed to be similar in number of endothelial vesicles and caveolae.

No obvious difference in ultrastructural characteristics was found between samples taken from mesometrial or antimesometrial aspects and taken far from or near to the trophectoderm (pregnant gilts only). Almost all fenestrations, however, were found on capillaries from the mesometrial aspect and close to the trophectoderm. The only exceptions were one capillary from the antimesometrial aspect of a pregnant Day 13 gilt and one from the mesometrial aspect devoid of trophectoderm of another pregnant Day 13 gilt, but the few fenestrated capillaries observed do not allow a strong conclusion to be drawn on that point.

Ferritin. Capillaries in EM sections from gilts injected with a ferritin solution through the ear vein seemed to be devoid of ferritin. Particles were not found in endothelial cells, stroma or capillary lumina, although red blood cells were sometimes covered with black specks. Furthermore, ferritin was not seen in sections that were not stained with lead citrate and uranyl acetate or in lumina of larger blood vessels far from the luminal epithelium. Thus, no information was obtained on the possible motion of ferritin molecules through the capillary wall from these sections.

Different results were obtained from the two gilts injected with a mixture of ferritin and Evans blue directly into a uterine artery. The first gilt injected lost blue coloration of the uterus almost immediately after injection and subepithelial capillaries and larger uterine blood vessels were devoid of ferritin particles. By contrast, the other gilt retained the blue coloration of the uterus until sampling time and the lumen of the endometrial capillaries of that gilt contained large amounts of ferritin (Fig. 2a). Ferritin was mainly found in the capillary lumen, sometimes encountered on the stromal side of the capillary wall, but not observed in junctional complexes between endothelial cells. Ferritin particles were frequent in endothelial vesicles and these structures occasionally appeared to evacuate their contents on the stromal side of the capillary wall (Fig. 2b). Transendothelial channels filled with ferritin particles were observed.

\section{Discussion}

Results from Expt 1 do not support the hypothesis of increased uterine vascular permeability during early porcine gestation. However, the gilts were in the middle of the luteal phase and vascular permeability may have increased for several days after ovulation in all gilts without any 


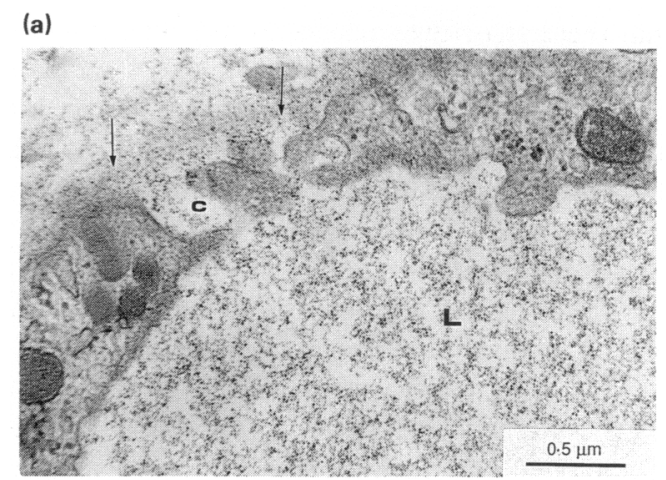

(b)

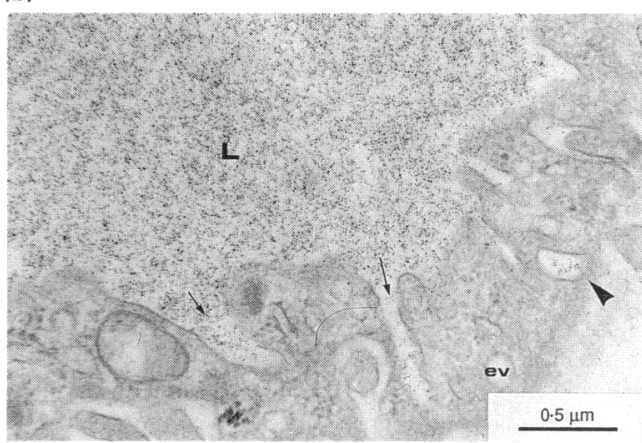

Fig. 2. Electron micrographs of subepithelial capillaries in the uterus of a pregnant Day 15 gilt injected with ferritin solution into a uterine artery before sampling. (a) The glandular epithelium lies beyond the upper left corner of the micrograph. The capillary lumen (L) is filled with ferritin particles. Ferritin is also found on the stromal side of the capillary wall (arrows) and inside a structure resembling a transendothelial channel (c). (b) The glandular epithelium of the uterus lies beyond the lower part of the micrograph. The capillary lumen $(\mathrm{L})$ is filled with ferritin particles. Ferritin is present in particularly well-developed caveolae (arrows), which could also represent endothelial channels in formation, and in some endothelial vesicles (ev). A caveola (arrowhead) seems to 'unload' its ferritin content on the stromal side of the capillary wall.

localization. If this was so, no difference in the radioactivity of endometrial tissues would be expected between pregnant and cycling gilts or between samples taken at different sites along the uterine horn. Alternatively, the methodology may need some modifications for use with species presenting an epitheliochorial, non-invasive type of placentation. High coefficients of variation (CV) for the radioactivity data clearly indicate that more repetition would be necessary to detect even large differences. Now that an estimate of variance is available, sample size calculations can be performed and these indicate that with a $\mathrm{CV}$ of $\sim 25 \%$, eight repetitions would be needed to detect a difference of $30 \%$ between means $(\sim 150$ c.p.m. for the uncorrected radioactivity in endometrial samples) at a level of significance of $P<0.05$ (Cochran \& Cox, 1957). Correction of the radioactivity of endometrial samples according to the radioactivity in plasma, blood or muscle was expected to reduce the coefficient of variation, which it did not do.

The amount and specific activity of the radioactive albumin injected was much lower than that used with rats (Kennedy, 1979) because of safety requirements for handling large amounts of radioactivity and disposal of contaminated blood and carcasses. Prolonged counting times ( $10 \mathrm{~min}$ ) were used in an attempt to compensate for the low radioactivity of the uterine samples (total counts $\sim 5000$ c.p.m. and well above background values), but the low specific activity of ${ }^{125}$ l-labelled human albumin was not really compensated for by a longer counting time. Some uterine horns 
were also perfused with normal saline to clear residual blood from the vascular bed, but this failed to affect overall results or to reduce variability.

Most work on vascular permeability has been conducted on rodents and rabbits. These species show a decidual reaction of the endometrium accompanying an invasive placentation, which is quite different from the attachment placentation observed in pigs. This reaction involves a strong oedema of the endometrium localized at implantation sites (Psychoyos, 1973; Sartor, 1980). Hence, an increase in permeability of the capillaries might be a prerequisite for the decidual reaction without being essential per se for implantation or attachment, and plasma albumin leaking into the endometrial stroma could be a strong instigator of that oedema. No significant difference was found for the dry matter content of porcine endometrial samples taken on either Day 13 or 15 of the cycle and pregnancy, suggesting the absence of a strong motion of water from blood vessels into uterine tissues at or near attachment sites during the initial stage of placentation.

Capillary ultrastructure did not differ markedly between pregnant and cycling gilts or between Days 13 and 15, contrary to what had been found previously (Keys \& King, 1988, 1990). However, results of the previous and current investigations do agree that samples coming from mesometrial and antimesometrial aspects of the uterine horn were not particularly different. Keys \& King (1990) selected specimens close to the embryonic disk and observed more samples from what is probably the most reactive region.

Abundant endothelial fenestrations that characterized endometrial capillaries in pregnant gilts slaughtered on Day 16 (Keys \& King, 1988, 1990) were rarely observed in the four gilts slaughtered on Day 15 in the current study (3.2\% of all the capillaries examined). Keys \& King (1988) reported that differences between cycling and pregnant gilts were particularly noticeable on Day 16 compared with Day 13. In the present study, gilts were sampled on Day 15 instead of Day 16, suggesting that capillaries from pregnant and cycling gilts undergo similar changes until Day 15. Thereafter, these changes become more accentuated in pregnant gilts, but gradually disappear in cycling gilts.

Endothelial vesicles were frequent in the present as well as in previous studies (Keys \& King, 1988, 1990). They were particularly numerous in capillaries presenting attenuated areas and adjacent to the epithelial basal lamina. Endothelial vesicles, because of their capacity to transfer large molecules through the capillary wall, have been associated with the large-pore system (Bruns $\&$ Palade, 1968) that would allow the passage of macromolecules as well as small molecules and fluid (Landis \& Pappenheimer, 1963). On the contrary, fenestrations with diaphragms have been shown to be less permeable and, therefore, were associated with the small-pore system responsible for the transfer of only smaller molecules and fluid (Bruns \& Palade, 1968; Clementi \& Palade, 1969). Although the complete dynamics of the transformation of endometrial capillaries in pigs has not yet been studied, it seems that the first signs of increased vascular permeability are an attenuation of the capillary wall and an increase in the number of endothelial vesicles. These signs seem to occur initially to the same extent in pregnant and cycling gilts and on the meso- and antimesometrial aspects of the uterine horn, suggesting that they are under the influence of progesterone. As gestation progresses, the attenuation of the capillary walls plus the number of endothelial vesicles and fenestrated areas increase. These particular changes could be triggered by oestrogens of embryonic origin, by the maintenance of progesterone secretion or by a combination of factors possibly involving prostaglandins and other conceptus secretory products. The transfer of large molecules through the capillary wall was demonstrated by the presence of ferritin on the stromal side of the capillaries. Ferritin was particularly abundant in endothelial vesicles. On some occasions, vesicles were seen 'unloading' their ferritin between the endothelial cell and the endothelial basal lamina.

Multilayered endothelial basal lamina are associated with endothelial cell injuries (Pierce \& Nakane, 1969; Vracko \& Benditt, 1972) or angiogenic stimuli (Findlay, 1987). The effect of angiogenic stimuli on the ultrastructure of the endothelial basal lamina (Findlay, 1987) may provide a plausible explanation for the formation of a multilayered basal lamina underlying 
endothelial cells of the pig endometrium. Indeed, this would be in accord with increased vascularization of the endometrium proposed to occur in early pregnancy in all mammals (Amoroso, 1952). Projections of the endothelial cells through the endothelial basal lamina were occasionally seen and they might have a role in the transformation of the endothelial basal lamina.

The substantial variances associated with quantitative measurements in this study emphasized the need for larger samples to reduce the probability of type II errors. The results also illustrate that placentation is a dynamic and rapidly progressing phenomenon, with little difference between capillary beds of cyclic and pregnant gilts on Day 15, but dramatic modifications one day later.

The authors thank D. Wey and C. Chapeau for excellent technical assistance and L. Laforest for help during preparation of the manuscript. Financial support was provided by the Natural Sciences and Engineering Research Council of Canada and the Ontario Ministry of Agriculture and Food.

\section{References}

Amoroso, E.C. (1952) Placentation. In Marshall's Phrsiology of Reproduction, 3rd edn, vol. 2, pp. 127 311. Ed. A. S. Parkes. Longmans, London.

Anderson, V.L. \& McLean, R.A. (1974) In Design of Experiments, a Realistic Approach, pp. 17-23. Marcel Dekker Inc, New York.

Bitton-Casimiri, V., Vassent, G. \& Psychoyos, A. (1965) Réponse vasculaire de l'utérus au traumatisme au cours de la pseudogestation chez la ratte. CR Acad. Sci. Paris 261, 3474-3477.

Boshier, D.P. (1970) The pontamine blue reaction in pregnant sheep uteri. J. Reprod. Fert. 22, 595 596.

Bruns, R.R. \& Palade, G.E. (1968) Studies on blood capillaries. II. Transport of ferritin molecules across the wall of muscle capillaries. J. Cell Biol. 37, $277-299$.

Clementi, F. \& Palade, G.E. (1969) Intestinal capillaries. 1. Permeability to peroxidase and ferritin. J. Cell Biol. 41, 33-58.

Cochran, W.G. \& Cox, G.M. (1957) In Experimental Designs, 2nd edn, pp. 1 6l1. John Wiley \& Sons, New York

Findlay, J.K. (1987) Angiogenesis in reproductive tissues. J. Endoc'r. 111, 357-366.

Finn, C.A. \& McLaren, A. (1967) A study of the early stages of implantation in mice. J. Reprod. Fert. 13, 259267.

Hoffman, L.H., Di Pietro, D.L. \& Mckenna, T.J. (1978) Effects of indomethacin on uterine capillary permeability and blastocyst development in rabbits. Prostaglandins 15, 823-828.

Hoos, P.C. \& Hoffman, L.H. (1980) Temporal aspects of rabbit uterine vascular and decidual responses to blastocyst stimulation. Biol. Reprod. 23, 453459.

Kennedy, T.G. (1979) Prostaglandins and increased endometrial vascular permeability resulting from the application of an artificial stimulus to the uterus of the rat sensitized for the decidual cell reaction. Biol. Reprod. 20, 560-566.

Keys, J.L. \& King, G.J. (1988) Morphological evidence for increased uterine vascular permeability at the time of embryonic attachment in the pig. Biol. Reprod. 39, 473-487.

Keys, J.L. \& King, G.J. (1990) Microscopic examination of porcine conceptus-maternal interface between
Days 10 and 19 of pregnancy. Am. J. Anat. 188, 221238 .

Keys, J.L., King, G.J. \& Kennedy, T.G. (1986) Increased uterine vascular permeability at the time of embryonic attachment in pig. Biol. Reprod. 34, 405-41!.

Landis, E.M. \& Pappenheimer, J.R. (1963) Exchange of substances through the capillary walls. In Handhook of Physiology. Section 2, Circulation, vol. 2, pp. 961-975. Eds W. F. Hamilton \& P. Dow. American Physiology Society, Washington DC.

Orsini, M.W. ( 1964) Implantation: a comparison of conditions in the pregnant and pseudopregnant hamster. 5th Int. Congr. Anim. Reprod. AI, Trento 7, 309314.

Orsini, M.W. \& Donovan, B.T. (1971) Implantation and induced decidualization of the uterus in the guinea pig, as indicated by pontamine blue. Biol. Reprod. 5, $270-281$.

Parr, M.B. \& Parr, E.L. (1985) Permeability of the primary decidual zone in the rat uterus: studies using FITC labelled tracers. Biol. Reprod. 32, Suppl. 1, Abst 50.

Pierce, G.B. \& Nakane, P.K. (1969) Basement membranes: synthesis and deposition in response to cellular injury. Lab. Invest. 21, 27-41.

Psychoyos, A. (1960) La réaction déciduale est précédée de modifications précoces de la perméabilité capillaire de l'utérus. CR Soc. Biol. 154, 1384-1387.

Psychoyos, A. (1961) Perméabilité capillaire et décidualisation utérine. CR Soc. Biol. 252, 1515-1517.

Psychoyos, A. (1973) Hormonal control of ovoimplantation. Vitam. Horm. 31, 201-256.

Sartor, P. (1980) Cell proliferation and decidual morphogenesis. In Progress in Reproductive Biology, pp. 115 124. Eds F. Leroy, C. A. Finn, A. Psychoyos \& P. O. Hubinont. Karger, Basel, Switzerland.

Snedecor, G.W. \& Cochran, W.G. (1980) In Statistical Methods, 7th edn. Iowa University Press, Ames, IA, USA.

SAS User's Guide (1987) SAS Institute Inc. Cary, North Carolina, USA.

Vracko, R. \& Benditt, E.P. (1972) Basal lamina: the scaffold for orderly cell replacement. J. Cell Biol. 55, 406-419. 